\title{
Factors Associated with Adherence to and Treatment Duration of Erlotinib Among Patients with Non-Small Cell Lung Cancer
}

\author{
Lisa M. Hess, PhD; Anthony Louder, PhD; Katherine Winfree, PhD; Yajun E. Zhu, MS; \\ Ana B. Oton, MD; and Radhika Nair, PhD
}

\begin{abstract}
BACKGROUND: In lung cancer, there is an increasing number of oral agents available for patients; however, little is known about the factors associated with adherence to and treatment duration on oral medications in non-small cell lung cancer (NSCLC).

OBJECTIVE: To evaluate the clinical and demographic factors associated with adherence and treatment discontinuation, respectively, to oral oncolytics among patients with NSCLC.

METHODS: A retrospective, claims-based analysis of the Humana Research Database supplemented with medical chart review was conducted among patients with NSCLC who started an oral oncolytic between January 1, 2008, and June 30, 2013. Patients were required to be enrolled at least 1 year before the start of oral oncolytics and have no evidence of any oral oncolytic use during this period. Logistic regression models and Cox proportional hazard models were used to identify predictors associated with medication adherence and treatment duration, respectively.
\end{abstract}

RESULTS: Among all oral oncolytics, only the cohort starting on erlotinib had sufficient sample size $(n=1,452)$. A wide variety of factors were found to be associated with adherence. Low-income subsidy status, previous use of intravenous chemotherapy, and lower total baseline health care costs were significantly related to decreasing adherence (each $P<0.05$ ). Additionally, increasing patient out-of-pocket cost was associated with decreasing adherence to erlotinib $(P<0.0001)$. Factors significantly related to longer treatment duration included low-income subsidy status $(P<0.001)$ and having Medicare insurance, $(P=0.0004)$, dual eligibility (Medicare and Medicaid, $P=0.007)$, and higher erlotinib out-of-pocket costs $(P<0.0001)$.

CONCLUSIONS: There is a need for mechanisms to be in place to identify and address barriers to care. Future research should focus on evaluating and reducing any potential risk to patient outcomes that may be associated with low adherence to or shorter treatment duration on oral chemotherapy.

J Manag Care Spec Pharm. 2017;23(6):643-52

Copyright ( 2 2017, Academy of Managed Care Pharmacy. All rights reserved.

\section{What is already known about this subject}

Poor medication adherence is a concern across many health conditions

The reasons for nonadherence are complex and vary between conditions and patient populations.

Oral oncolytic therapy is an option often favorable to patients because of the ease of administration, but maintaining adherence is a concern.

\section{What this study adds}

Thirteen percent of patients receiving erlotinib therapy for nonsmall cell lung cancer were nonadherent.

A variety of factors including previous treatment, staging, other neoplasms, cost, geography, and insurance status were significantly associated with adherence or treatment duration on erlotinib therapy.

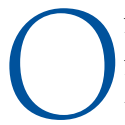
ncology treatments are rapidly evolving, with a rise in the availability of oral chemotherapy and biologic therapies. While patients tend to prefer the use of oral therapy, ${ }^{1}$ new challenges are presented with medication adherence that are not present with intravenous (IV) therapy. ${ }^{2}$ With IV administration, adherence is less of a concern as receipt of treatment is both observed and documented at each infusion. However, when the patient is responsible for taking the medication regularly at home, there is a risk that the medication is not always taken as prescribed. Patients may not refill medications as needed, doses may be missed or forgotten, and patients may accidentally take doses earlier or later than recommended. These factors may result in lower adherence, which may be associated with other poor patient outcomes (e.g., reduced efficacy, increased toxicity). For many chronic diseases, improving medication adherence is thought to help achieve positive patient outcomes and reduce health care costs. ${ }^{3}$

Nonadherent behavior has been identified in patients with a variety of cancers; furthermore, nonadherence was related to higher rates of hospitalizations and emergency department (ED) visits. ${ }^{4}$ Research has noted that patient forgetfulness, drug toxicity, and patient out-of-pocket costs are commonly associated with reduced adherence to oral oncolytics. ${ }^{5-8}$

In non-small cell lung cancer (NSCLC), there is an increasing number of oral agents available for patients, such as the epidermal growth factor receptor (EGFR) inhibitors erlotinib and afatinib. Additionally, gefitinib, crizotinib, ceritinib, and alectinib are available for patients with anaplastic lymphoma kinase mutations. ${ }^{2}$ Other oral agents are in clinical development targeting KRAS, MET, and ROS-1.9 With the growing availability of oral oncolytics, treatment options for patients are increased, especially medications with easier methods of administration. However, this also increases the potential for 
nonadherence or treatment discontinuation among patients with NSCLC.

Erlotinib is currently the most commonly prescribed oral agent in NSCLC. ${ }^{10}$ A small study $(\mathrm{n}=65)$ in the Netherlands found that overall adherence to erlotinib is high, ${ }^{11}$ but approximately $7 \%$ fell below a $90 \%$ adherence rate and $21 \%$ did not take the medication as prescribed; these patients were considered at risk for suboptimal outcomes. Other studies have evaluated programs to improve adherence to erlotinib. ${ }^{12,13}$ In these small studies (30 patients, respectively), adherence was high, but lower adherence was suggested to be a risk factor for worse patient outcomes. The factors associated with adherence were not fully explored in any of these lung cancer studies, and little is known regarding whether or not the findings related to health care cost reductions from other chronic illnesses hold true in lung cancer.

While adherence measures the use of a medication in accordance with the recommendations of the health care provider ${ }^{14}$ persistence is a measure of the duration of therapy..$^{15}$ In oncology, the time to treatment discontinuation should be related to disease progression or unacceptable toxicity, as many oral chemotherapy agents are developed for use until the time of disease progression as long as the patient tolerates the drug. However, it is possible that early discontinuation of medication occurs for reasons other than progression or toxicity and in turn is interpreted as low efficacy of treatment. If a physician is unaware that the oral medication is not being used as prescribed, the progression of the disease may be inappropriately attributed to lack of drug effect, and the physician may unnecessarily change therapy. Additionally, nonadherence and early discontinuation of treatment in some populations suggest an association with increased utilization of health care resources in other diseases (physician visits, number and duration of hospitalizations), ${ }^{16-18}$ but current data are lacking, and little is known related to resource utilization and adherence to oral cancer medications.

The aims of this study were to evaluate the clinical and demographic factors associated with adherence and treatment discontinuation, respectively, to oral oncolytics among patients with NSCLC. Erlotinib was selected from among the oral oncolytics available to patients with NSCLC due to prescribing patterns that allowed for an adequate sample size to be evaluated. Other oral agents, crizotinib and gefitinib, were each used by 10 or fewer patients in the database, and no patients were identified with use of afatinib or ceritinib. Therefore, this analysis was limited to patients who received erlotinib. Erlotinib was approved for recurrent or progressive NSCLC after failure of at least 1 chemotherapy regimen, as maintenance therapy, and as first-line therapy for patients with epidermal growth factor receptor (EGFR) mutation-positive tumors. However, in October 2016, the U.S. Food and Drug Administration restricted the indication to be limited to patients whose tumors expressed EGFR mutations for any line of therapy.

\section{Methods}

Data were obtained from the Humana Research Database, which contains enrollment, medical, and pharmacy claims information for persons enrolled with Humana, a health insurance company serving millions of people across the country through Medicare Advantage plans, stand-alone prescription drug plans, and commercial plan offerings. Additional data confirming the NSCLC diagnosis were obtained by medical chart review, including treatment received, disease stage, histology, mutation status, and date of death. All data were merged and linked by a unique patient identifier for analyses. The finalized protocol was approved by Schulman Associates Institutional Review Board Cincinnati, $\mathrm{OH}$.

\section{Study Design}

This retrospective longitudinal cohort study included patients enrolled in a Humana Medicare Advantage prescription drug (MA-PD) plan or commercial health plan with lung cancer who initiated erlotinib between January 1, 2008, and June 30, 2013 The date of the first erlotinib claim was defined as the index date for these cohorts. The study period was January 1, 2007, through June 30, 2014.

\section{Study Population}

The study population included patients between the ages of 18 and 89 years (due to privacy restrictions of the claims database) identified with at least 1 medical claim having an International Classification of Diseases, Ninth Revision, Clinical Modification (ICD-9-CM) code of 162.2-162.9 within 30 days of the index date. Patients were required to have a 12-month preindex period with no use of any oral oncolytic. Patients were required to be enrolled for at least 1 day post-index and were followed until 1 of the following occurred: disenrollment from the health plan, death, or end of the study period, whichever occurred first. Patients were excluded if they were treated with a medication used for the treatment of small cell lung cancer (SCLC) in either the pre- or post-index period.

\section{Statistical Analysis}

Adherence to erlotinib was measured by medication possession ratio (MPR). ${ }^{19,20}$ MPR was calculated per patient as the total number of days supply of all prescriptions for erlotinib divided by the number of days between the first fill and the last refill plus the days supply of the last refill. A minimum of 2 prescription claims for erlotinib was required for an MPR measure to be calculated. Nonadherence was defined as patients having an MPR of 0.80 (80\%) or less, consistent with previous research and with quality improvement metrics..$^{21,22}$

Treatment duration was measured as the number of days of continuous erlotinib therapy before discontinuation. Gap days were identified between fills where the fill date for the subsequent fill is greater than the run-out date (fill date plus days 
supply) for the previous fill. Patients were considered to have discontinued therapy if there was a gap in therapy of at least 60 days. Patients were censored from the treatment duration analyses if they discontinued enrollment during erlotinib use for reasons other than death.

Logistic regression models were used to identify predictors associated with adherence (> $80 \%$ adherent or $\leq 80 \%$ adherent). Cox proportional hazards regression models were used to measure factors associated with duration of treatment with erlotinib therapy, measured as a continuous variable as the duration of therapy. Covariates in the model included factors in the database that may be associated with adherence or persistence: age, gender, race/ethnicity, geographic region, population density, low-income subsidy status, health care plan type, Deyo-Charlson Comorbidity Index (DCCI), diagnosis of metastatic disease, diagnosis of other cancers, line of therapy, baseline total health care costs, and erlotinib out-of-pocket costs. Models were run for the full cohort and for those who had chart data available (sensitivity analysis), respectively.

All data analyses were conducted using SAS Enterprise Guide 5.1 (SAS Institute, Cary, NC). Statistical significance was defined as $P<0.05$.

\section{Results}

A total of 1,452 patients were identified in the claims data with erlotinib use, of whom 729 had complete chart information for the erlotinib analysis (Tables 1 and 2, Figure 1). The majority of the erlotinib cohort had Medicare coverage (89\% overall cohort; $88 \%$ of those with chart data), were white $(72 \%)$, and were residents in the southern region of the United States (65\% overall cohort; $62 \%$ with chart data). Among the erlotinib patients with chart data, most were diagnosed with stage IV disease (58.3\%); adenocarcinoma (64.1\%) and squamous cell carcinoma (21.1\%) were the most common histological types of NSCLC.

\section{Adherence and Duration of Treatment}

Adherence to and duration of treatment with erlotinib therapy overall, by line of therapy (erlotinib), and for those with chart data are reported in Table 3. All adherence analyses were limited to the 1,088 patients with 2 or more claims to allow for adherence calculations. Overall, $12.5 \%$ of patients were nonadherent. Nonadherence did not vary much by line of therapy (14.3\% when erlotinib was used as first-line therapy; $11.5 \%$ were nonadherent in the second-line setting) or for those with chart data (13.5\% nonadherent). The mean duration of therapy did not vary between the overall cohort (203.7 days; standard deviation $[S D]=256.4$ days) and the subset of patients with chart data (213.7 days; SD =256.8) across lines of therapy. In the first-line setting, patients continued therapy for 235.7 days ( $S D=300.4)$ and in the second-line setting for 184.6 days $(S D=224.1)$. The reasons for discontinuation were not known or recorded in the dataset.
Only 28.1\% ( $\mathrm{n}=205$ ) of patients underwent EGFR testing in the cohort; among this group, 112 (54.6\%) were confirmed to be EGFR-positive. Of the EGFR-positive patients, $12.8 \%$ were nonadherent versus less than $10 \%$ of the EGFR-unknown group (EGFR status was only reported if positive in the data).

Factors Associated with Adherence. Table 4 provides results of the evaluation of the predictors of adherence and treatment duration from the claims data for patients with 2 or more erlotinib fills. Receipt of low-income subsidy (Medicare Advantage), previous use of IV chemotherapy, and costs (baseline total health care costs and patient out-of-pocket costs) were statistically significant predictors of erlotinib adherence. Low-income subsidy recipients and patients who had received IV chemotherapy had $44.0 \%$ and $27.0 \%$ lower odds of being adherent than patients who did not have those characteristics, respectively. For every $\$ 1,000$ increase in baseline health care costs, the odds of being adherent increased by $3.0 \%$. With every increase in $\$ 100$ for out-of-pocket erlotinib costs per prescription, the odds of being adherent decreased by $3.0 \%$ (Table 4).

For the sensitivity analysis of patients with chart data (Table 5), being a low-income subsidy recipient was no longer a statistically significant factor associated with adherence (odds ratio $[\mathrm{OR}]=0.72,95 \%$ confidence interval $[\mathrm{CI}]=0.34-1.55 ; \mathrm{P}=0.41$ ). Diagnosis of other neoplasms almost doubled the odds of patients being adherent $(\mathrm{OR}=1.95,95 \% \mathrm{CI}=1.24-3.06 ; P=0.004)$. Each $\$ 100$ increase in out-of-pocket costs was associated with a $6.0 \%$ decrease in adherence $(\mathrm{OR}=0.94,95 \% \mathrm{CI}=0.91-0.97$; $P=0.0001$ ). Patients in stage IV NSCLC had a $59.0 \%$ greater odds of being adherent than patients with NSCLC in other stages of the cancer $(\mathrm{OR}=1.59,95 \% \mathrm{CI}=1.03-2.44 ; \mathrm{P}=0.04)$.

Factors Associated with Duration of Treatment. In the overall cohort, among patients (plan plus patient paid) with Medicare insurance, patients who were low-income subsidy eligible (hazard ratio $[\mathrm{HR}]=2.33,95 \% \mathrm{CI}=1.67-3.26 ; P<0.0001$ ) or dual eligible (Medicare and Medicaid) were more likely to remain on erlotinib for a longer duration (HR $=2.09,95 \%$ $C I=1.48-2.96 ; P<0.0001)$. However, compared to patients with Medicare coverage, those enrolled in commercial plans had $52.0 \%$ lower odds of remaining on therapy ( $\mathrm{OR}=0.48,95 \%$ $\mathrm{CI}=0.35-0.66 ; P<0.001)$. For every $\$ 100$ increase in erlotinib out-of-pocket costs, the odds of a patient remaining on therapy increased by $15.0 \%(\mathrm{OR}=1.15,95 \% \mathrm{CI}=1.13-1.17 ; \mathrm{P}<0.001)$. Additionally, patients living in suburban areas had a reduced duration of treatment versus those in rural areas $(\mathrm{OR}=0.73$, 95\% CI $=0.56-0.95 ; P=0.02$, Table 4). Results were similar for the sensitivity analysis of patients with chart data $(O R=0.40$, 95\% CI $=0.24-0.66 ; P=0.0004$ for patients enrolled in commercial versus Medicare plans and $\mathrm{OR}=1.17,95 \% \mathrm{CI}=1.14$ 1.19; $P<0.0001$ for out-of-pocket costs). 
TABLE 1 Baseline Demographic and Clinical Characteristics of Study Population

\begin{tabular}{|c|c|c|c|c|c|c|c|c|}
\hline \multirow{2}{*}{$\begin{array}{ll}\text { Characteristic } \\
\text { Mean age, years }( \pm S D)\end{array}$} & \multicolumn{2}{|c|}{$\begin{array}{c}\text { Erlotinib Cohort } \\
n=1,452\end{array}$} & \multicolumn{2}{|c|}{$\begin{array}{l}\text { Erlotinib Cohort } \\
\text { with } 2+\text { Claims } \\
\text { n }=1,088\end{array}$} & \multicolumn{2}{|c|}{$\begin{array}{l}\text { Erlotinib Cohort } \\
\text { with Chart Data } \\
\qquad \mathbf{n}=729\end{array}$} & \multicolumn{2}{|c|}{$\begin{array}{l}\text { Erlotinib Cohort with } \\
\text { Chart Data and 2+ } \\
\text { Claims, } n=572\end{array}$} \\
\hline & 71.9 & $( \pm 9.0)$ & 71.8 & $( \pm 8.9)$ & 71.5 & $( \pm 9.3)$ & 71.6 & $( \pm 9.0)$ \\
\hline \multicolumn{9}{|l|}{ Gender, n (\%) } \\
\hline Male & 667 & $(45.9)$ & 482 & $(44.3)$ & 326 & $(44.7)$ & 249 & $(43.5)$ \\
\hline Female & 785 & $(54.1)$ & 606 & $(55.7)$ & 403 & $(55.3)$ & 323 & $(56.5)$ \\
\hline \multicolumn{9}{|l|}{ Race/ethnicitya, n (\%) } \\
\hline White & 1,049 & $(72.2)$ & 773 & $(71.0)$ & 527 & $(72.3)$ & 409 & $(71.5)$ \\
\hline Black & 183 & $(12.6)$ & 148 & (13.6) & 86 & (11.8) & 74 & (12.9) \\
\hline Hispanic & 17 & $(1.2)$ & 11 & $(1.0)$ & \multicolumn{2}{|c|}{$<10$} & 5 & $(0.9)$ \\
\hline Other & 42 & $(2.9)$ & 37 & (3.4) & 23 & $(3.2)$ & 21 & $(3.7)$ \\
\hline Unknown & 161 & $(11.1)$ & 119 & $(10.9)$ & 86 & $(11.8)$ & 63 & $(11.0)$ \\
\hline \multicolumn{9}{|l|}{ Geographic region, $\mathrm{n}(\%)$} \\
\hline Northeast & 34 & $(2.3)$ & 24 & $(2.2)$ & 18 & $(2.5)$ & 15 & $(2.6)$ \\
\hline Midwest & 358 & $(24.7)$ & 269 & $(24.7)$ & 185 & $(25.4)$ & 135 & $(23.6)$ \\
\hline South & 936 & $(64.5)$ & 704 & $(64.7)$ & 455 & $(62.4)$ & 366 & $(64.0)$ \\
\hline West & 115 & $(7.9)$ & 83 & $(7.6)$ & 65 & $(8.9)$ & 50 & $(8.7)$ \\
\hline \multicolumn{9}{|l|}{ Population density, n (\%) } \\
\hline Rural & 154 & $(10.6)$ & 113 & $(10.4)$ & 82 & $(11.2)$ & 66 & $(11.5)$ \\
\hline Suburban & 329 & $(22.7)$ & 240 & $(22.1)$ & 167 & $(22.9)$ & 126 & $(22.0)$ \\
\hline Urban & 960 & $(66.1)$ & 727 & $(66.8)$ & 474 & $(65.0)$ & 374 & $(65.4)$ \\
\hline \multicolumn{9}{|l|}{ Insurance plan type, $\mathrm{n}(\%)$} \\
\hline Commercial & 161 & $(11.1)$ & 120 & $(11.0)$ & 87 & (11.9) & 64 & $(11.2)$ \\
\hline Medicare & 1,291 & $(88.9)$ & 968 & $(89.0)$ & 642 & $(88.1)$ & 508 & $(88.8)$ \\
\hline \multicolumn{9}{|c|}{ Low-income subsidy and dual eligible (Medicare) ${ }^{\mathrm{b}}$} \\
\hline Low-income subsidy only & 74 & $(5.7)$ & 49 & $(5.1)$ & 39 & $(6.1)$ & 27 & $(5.3)$ \\
\hline Dual eligible only & 66 & $(5.1)$ & 47 & $(4.9)$ & 28 & $(4.4)$ & 21 & $(4.1)$ \\
\hline Low-income subsidy and dual eligible & 170 & $(13.2)$ & 124 & $(12.8)$ & 83 & $(12.9)$ & 61 & $(12.0)$ \\
\hline \multicolumn{9}{|l|}{ Year of index claim } \\
\hline 2008 & 256 & $(17.6)$ & 188 & $(17.3)$ & 94 & $(12.9)$ & 76 & $(13.3)$ \\
\hline 2009 & 286 & $(19.7)$ & 203 & $(18.7)$ & 128 & $(17.6)$ & 96 & $(16.8)$ \\
\hline 2010 & 265 & $(18.3)$ & 204 & $(18.8)$ & 148 & $(20.3)$ & 120 & $(21.0)$ \\
\hline 2011 & 295 & $(20.3)$ & 222 & $(20.4)$ & 159 & $(21.8)$ & 121 & $(21.2)$ \\
\hline 2012 & 218 & $(15.0)$ & 165 & $(15.2)$ & 121 & (16.6) & 94 & $(16.4)$ \\
\hline 2013 & 132 & $(9.1)$ & 106 & $(9.7)$ & 79 & $(10.8)$ & 65 & $(11.4)$ \\
\hline DCCI mean $( \pm$ SD) & 5.9 & $( \pm 3.3)$ & 5.7 & $( \pm 3.4)$ & 5.9 & $( \pm 3.3)$ & 5.8 & $( \pm 3.4)$ \\
\hline Median, interquartile range Q1-Q3 & 7.0 & $.0-8.0$ & 6.0 & $.0-8.0$ & 7.0 & $0-8.0$ & 6.5 & $.0-8.0$ \\
\hline Min., max. & \multicolumn{2}{|c|}{0,15} & \multicolumn{2}{|c|}{0,15} & \multicolumn{2}{|c|}{0,14} & \multicolumn{2}{|c|}{0,14} \\
\hline Smoking status, claims-based & 677 & $(46.6)$ & 514 & $(47.2)$ & 346 & $(47.5)$ & 277 & $(48.4)$ \\
\hline Diagnosis of metastatic disease & 986 & $(67.9)$ & 718 & $(66.0)$ & 507 & $(69.5)$ & 389 & $(68.0)$ \\
\hline Lymph nodes & 330 & $(22.7)$ & 249 & $(22.9)$ & 156 & $(21.4)$ & 128 & $(22.4)$ \\
\hline Respiratory or digestive system & 554 & $(38.2)$ & 393 & $(36.1)$ & 271 & $(37.2)$ & 208 & (36.4) \\
\hline Other and unspecified sites & 584 & $(40.2)$ & 408 & $(37.5)$ & 304 & $(41.7)$ & 222 & $(38.8)$ \\
\hline \multicolumn{9}{|c|}{$\begin{array}{l}\text { Note: Columns may not add up to } 100 \% \text { due to missing/unavailable data from some patients. } \\
\text { aRacelethnicity not available for patients enrolled in commercial plans. } \\
\text { bercentages based on Medicare population as denominator. } \\
\text { DCCI=Deyo-Charlson Comorbidity Index; max = maximum; min= minimum; } Q=\text { quartiles; } S D=\text { standard deviation. }\end{array}$} \\
\hline
\end{tabular}

In the subset of patients who were tested for EGFR, those with EGFR-positive tumors remained on therapy for an average of 338.5 days $(S D=309.6)$ versus those with negative or unknown EGFR status who remained on therapy for an average of 137.9 days $(\mathrm{SD}=116.3 ; P<0.0001)$.

\section{Discussion}

There is a need to better understand the factors associated with reduced adherence if successful programs are to be developed to improve patient adherence to oral oncolytics in lung cancer. 


\section{TABLE 2 Baseline Chart-Obtained Characteristics of the Erlotinib Cohort}

\begin{tabular}{|c|c|c|}
\hline Characteristic & $\begin{array}{l}\text { Erlotinib Cohort with Chart Data } \\
\qquad \mathrm{n}=729\end{array}$ & $\begin{array}{l}\text { Erlotinib Cohort with Chart Data and 2+ Claims } \\
\qquad \mathrm{n}=572\end{array}$ \\
\hline \multicolumn{3}{|l|}{ Smoking status, chart-based, n (\%) } \\
\hline Past smoker & $(51.2)$ & $(48.8)$ \\
\hline Current smoker & $(21.5)$ & $(22.6)$ \\
\hline Non-smoker & $(17.1)$ & $(18.4)$ \\
\hline Unknown/not documented & $(10.2)$ & $(10.3)$ \\
\hline \multicolumn{3}{|l|}{ Histology, chart-based, n (\%) } \\
\hline Adenocarcinoma & $(64.1)$ & $(64.7)$ \\
\hline Squamous cell & $(21.1)$ & $(21.3)$ \\
\hline Large cell carcinoma & $(1.5)$ & $<10$ \\
\hline Other & $(1.6)$ & $<10$ \\
\hline Unknown/not documented & $(11.7)$ & $(11.2)$ \\
\hline \multicolumn{3}{|l|}{ Staging, chart-based, n (\%) } \\
\hline Not documented & $(20.4)$ & $(21.3)$ \\
\hline Documented & $(79.6)$ & $(78.7)$ \\
\hline Stage 0 & $(0.0)$ & $(0.0)$ \\
\hline Stage I & $(8.8)$ & $(10.0)$ \\
\hline Stage IA & $(3.8)$ & $(4.7)$ \\
\hline Stage IB & $(5.0)$ & $(5.3)$ \\
\hline Stage II & $(5.5)$ & $(5.3)$ \\
\hline Stage IIA & $(2.9)$ & $(2.9)$ \\
\hline Stage IIB & $(2.6)$ & $(2.4)$ \\
\hline Stage III & $(27.4)$ & $(28.4)$ \\
\hline Stage IIIA & $(12.6)$ & $(12.7)$ \\
\hline Stage IIIB & $(14.8)$ & (15.8) \\
\hline Stage IV & $(58.3)$ & $(56.2)$ \\
\hline \multicolumn{3}{|l|}{ Genetic mutation testing, chart-based, ${ }^{a}$ n (\%) } \\
\hline Genetic mutation testing performed & $(30.9)$ & $(31.6)$ \\
\hline KRAS tested & $(5.9)$ & $(5.9)$ \\
\hline KRAS positive & $(23.3)$ & $<10$ \\
\hline KRAS unknown/not documented & $(94.1)$ & $(94.1)$ \\
\hline EGFR tested & $(28.1)$ & $(28.7)$ \\
\hline EGFR positive & $(54.6)$ & $(57.3)$ \\
\hline EGFR unknown/not documented & $(71.9)$ & $(71.3)$ \\
\hline ALK tested & $(12.6)$ & $(12.2)$ \\
\hline ALK positive & $<10$ & $<10$ \\
\hline ALK unknown/not documented & $(87.4)$ & $(87.8)$ \\
\hline HER2 & $<10$ & $<10$ \\
\hline HER2 positive & $(0.0)$ & $(0.0)$ \\
\hline HER2 unknown/not documented & $(99.3)$ & $(99.3)$ \\
\hline BRAF tested & $<10$ & $<10$ \\
\hline BRAF positive & $(0.0)$ & $(0.0)$ \\
\hline BRAF unknown/not documented & $(99.0)$ & $(99.0)$ \\
\hline PI3KCA & $<10$ & $<10$ \\
\hline PI3KCA positive & $(0.0)$ & $(0.0)$ \\
\hline P13KCA unknown/not documented & $(99.0)$ & $(99.0)$ \\
\hline MAPK kinase 1 (MAP2Kl or MEKl) tested & $(0.0)$ & $(0.0)$ \\
\hline MAPK unknown/not documented & $729 \quad(100.0)$ & $572 \quad(100.0)$ \\
\hline
\end{tabular}

The literature reports a wide range in adherence to therapy in some cancers, including NSCLC (29\%-93\%).,11-13 In the current study, adherence was reported to be above $80 \%$ and only varied slightly depending on line of therapy. The reasons for high adherence in some of the studies may be due to sample sizes. Another major difference is that the current study reports data from claims, which indicated the patient filled the prescription. In contrast, most studies in the 
TABLE 2 Baseline Chart-Obtained Characteristics of the Erlotinib Cohort (continued)

\begin{tabular}{|c|c|c|c|c|c|c|c|c|}
\hline \multirow{4}{*}{$\begin{array}{l}\text { Characteristic } \\
\begin{array}{l}\text { Genetic testing by year of index } \\
\text { erlotinib, } \mathbf{n}(\%)\end{array} \\
2008 \\
2009\end{array}$} & \multicolumn{4}{|c|}{$\begin{array}{l}\text { Erlotinib Cohort with Chart Data } \\
\qquad \mathrm{n}=729\end{array}$} & \multicolumn{4}{|c|}{$\begin{array}{l}\text { Erlotinib Cohort with Chart Data and 2+ Claims } \\
\qquad \mathrm{n}=572\end{array}$} \\
\hline & \multicolumn{2}{|c|}{$\mathrm{n}=729$} & \multicolumn{2}{|c|}{$\begin{array}{c}\text { Tested } \\
\mathrm{n}=225(30.9 \%)\end{array}$} & \multicolumn{2}{|c|}{$\begin{array}{l}2+\text { claims } \\
\mathbf{n}=572\end{array}$} & \multirow{2}{*}{\multicolumn{2}{|c|}{$\begin{array}{l}\text { Tested and 2+ claims } \\
\qquad \mathbf{n}=\mathbf{1 8 1} \\
<10\end{array}$}} \\
\hline & & (12.9) & & & & (13.3) & & \\
\hline & 128 & $(17.6)$ & & $(14.8)$ & 96 & (16.8) & 16 & $(16.7)$ \\
\hline 2010 & 148 & $(20.3)$ & 35 & (23.6) & 120 & $(21.0)$ & 31 & $(25.8)$ \\
\hline 2011 & 159 & $(21.8)$ & & $(40.3)$ & 121 & $(21.2)$ & 48 & $(39.7)$ \\
\hline 2012 & 121 & (16.6) & 55 & $(45.5)$ & 94 & (16.4) & 40 & $(42.6)$ \\
\hline 2013 & 79 & $(10.8)$ & 45 & $(57.0)$ & 65 & (11.4) & 39 & $(60.0)$ \\
\hline
\end{tabular}

${ }^{a}$ Numbers do not add up to $100 \%$ due to missing data and multiple tests per patient; cells with sample sizes $<10$ are not reported in accordance with privacy requirements for this dataset.

$A L K=$ anaplastic lymphoma kinase receptor; BRAF = V-raf murine sarcoma viral oncogene homolog B1; EGFR=epidermal growth factor receptor; HER2=human epidermal growth factor receptor 2; KRAS = Kirsten rat sarcoma viral oncogene; PI3CKA = PIK3 catalytic protein alpha.

\section{FIGURE 1 Attrition Flow Diagram}

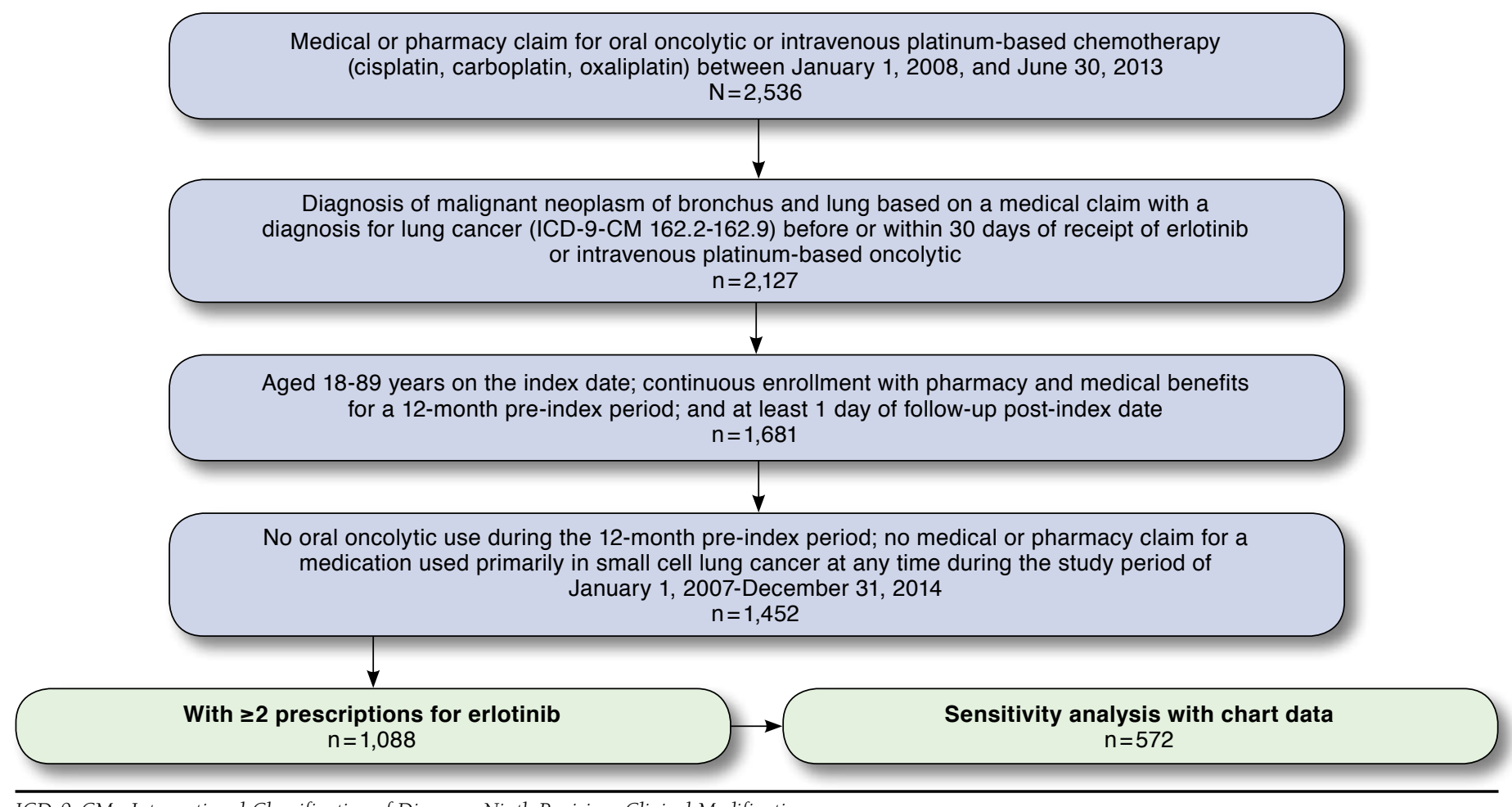

ICD-9-CM=International Classification of Diseases, Ninth Revision, Clinical Modification.

literature are based on patient self-report, which indicates whether the patient actually took the medication. However, self-report may be limited by recall bias and is known to overestimate adherence. ${ }^{23}$ Claims data are well suited for adherence studies due to several factors, such as that they generally include large sample sizes, provide longitudinal information at the patient level of every fill and refill of each prescription and the days' supply provided, and reflect the actual practice of care in uncontrolled settings. When combined with electronic health records, the researcher is able to verify the drug was prescribed (e.g., not a coding error in the claims database) and can verify the condition for which the patient is being treated. ${ }^{24}$

While there is literature on adherence to therapy for NSCLC, not much has been reported on factors affecting adherence to oral NSCLC therapies, in particular erlotinib. Based solely on administrative claims data, previous IV therapy, belonging 
TABLE 3 Descriptive Analyses of Adherence to and Duration of Treatment with Erlotinib

\begin{tabular}{|c|c|c|c|c|}
\hline Measure & $\begin{array}{c}\text { Erlotinib Cohort } \\
n=1,452\end{array}$ & $\begin{array}{l}\text { First-Line Erlotinib } \\
\qquad \mathbf{n}=551\end{array}$ & $\begin{array}{l}\text { Second-Line Erlotinib } \\
\qquad \mathbf{n}=901\end{array}$ & $\begin{array}{c}\text { Erlotinib Cohort } \\
\text { with Chart Data } \\
\qquad \mathbf{n}=729\end{array}$ \\
\hline 2 or more erlotinib claims ${ }^{\mathrm{a}}, \mathrm{n}(\%)$ & 1,088 & $(73.9)$ & $(75.6)$ & $(78.5)$ \\
\hline MPR, mean $( \pm \mathrm{SD})$ & $( \pm 0.16)$ & $( \pm 0.17)$ & $( \pm 0.16)$ & $( \pm 0.16)$ \\
\hline Median, interquartile range Q1-Q3 & $1.01,0.93-1.06$ & $1.00,0.92-1.05$ & $1.01,0.93-1.07$ & $1.01,0.94-1.06$ \\
\hline Min., $\max$ & $0.04,1.90$ & $0.04,1.55$ & $0.18,1.90$ & $0.04,1.90$ \\
\hline$\%$ Nonadherent $(\mathrm{MPR} \leq 80 \%)^{\mathrm{b}}, \mathrm{n}(\%)$ & $(12.5)$ & (14.3) & (11.5) & $(13.5)$ \\
\hline Gap days in therapy, mean $( \pm$ SD) & $36.1 \quad( \pm 114.3)$ & $47.0 \quad( \pm 146.0)$ & $( \pm 89.7)$ & $36.2( \pm 112.9)$ \\
\hline Median, interquartile range Q1-Q3 & $5,0-26$ & $8,0-38$ & $5,0-21$ & $6,0-29$ \\
\hline Min., $\max$ & $0,2,131$ & $0,2,131$ & 0,1205 & $0,2,131$ \\
\hline Deceased during post-period ${ }^{\mathrm{a}}, \mathrm{n}(\%)$ & $(77.5)$ & $(74.7)$ & $(79.1)$ & $(76.6)$ \\
\hline Censored during post-period ${ }^{\mathrm{a}}, \mathrm{n}(\%)$ & $(16.9)$ & $(16.7)$ & $(17.0)$ & $(16.4)$ \\
\hline Persistence-days of therapy, mean $( \pm$ SD) & $203.7 \quad( \pm 256.4)$ & $235.7 \quad( \pm 300.4)$ & $184.6 \quad( \pm 224.1)$ & $213.7 \quad( \pm 256.8)$ \\
\hline Median, interquartile range Q1-Q3 & $109,65-218$ & $120,67-255$ & $96,63-195$ & $114,65-251$ \\
\hline Min., $\max$. & $8,2,146$ & $8,2,146$ & $27,1,646$ & $27,2,146$ \\
\hline Discontinuation (60-day gap) ${ }^{\mathrm{a}}$, n (\%) & $(6.7)$ & $(8.6)$ & (5.6) & $(7.2)$ \\
\hline
\end{tabular}

a Denominator is total cohort.

${ }^{b}$ Denominator is the subgroup with 2 or more erlotinib claims.

max = maximum; min = minimum; $M P R=$ medication possession ratio; $S D=$ standard deviation; $Q=q u a r t i l e$.

TABLE 4 Evaluation of Potential Predictors of Adherence to and Duration of Treatment with Oral Erlotinib $(\mathrm{N}=1,088)$

\begin{tabular}{|c|c|c|c|c|c|c|}
\hline \multirow[b]{2}{*}{ Parameter } & \multicolumn{3}{|c|}{ Adherence $^{\mathrm{a}}$} & \multicolumn{3}{|c|}{ Persistence } \\
\hline & OR & $(95 \% \mathrm{CI})$ & $P$ Value & HR & $(95 \% \mathrm{CI})$ & $P$ Value \\
\hline Age, years & 1.01 & $(0.99-1.03)$ & 0.26 & 0.99 & $(0.98-1.00)$ & 0.22 \\
\hline Gender (male vs. female) & 1.02 & $(0.80-1.30)$ & 0.88 & 1.07 & $(0.93-1.24)$ & 0.33 \\
\hline Race/ethnicity (black/other vs. white) & 1.26 & $(0.91-1.75)$ & 0.16 & 0.87 & $(0.72-1.05)$ & 0.1535 \\
\hline Patient's geographic region (Northeast vs. South) & 2.07 & $(1.00-4.27)$ & 0.07 & 0.59 & $(0.35-1.00)$ & 0.05 \\
\hline Patient's geographic region (West vs. South) & 1.18 & $(0.76-1.83)$ & 0.76 & 0.83 & $(0.63-1.09)$ & 0.18 \\
\hline Patient's geographic region (Midwest vs. South) & 1.00 & $(0.75-1.32)$ & 0.11 & 1.04 & $(0.88-1.22)$ & 0.65 \\
\hline Population density (urban vs. rural) & 1.07 & $(0.70-1.62)$ & 0.49 & 0.81 & $(0.64-1.02)$ & 0.08 \\
\hline Population density (suburban vs. rural) & 1.38 & $(0.87-2.19)$ & 0.07 & 0.73 & $(0.56-0.95)$ & 0.02 \\
\hline Low-income subsidy recipient (Medicare Advantage only) & 0.56 & $(0.36-0.89)$ & 0.01 & 2.33 & $(1.67-3.26)$ & $<0.0001$ \\
\hline Dual eligible recipient (Medicare Advantage only) & 1.20 & $(0.78-1.85)$ & 0.42 & 2.09 & $(1.48-2.96)$ & $<0.0001$ \\
\hline Commercial vs. Medicare & 1.06 & $(0.62-1.80)$ & 0.84 & 0.48 & $(0.35-0.66)$ & $<0.0001$ \\
\hline Deyo-Charlson Comorbidity Index & 1.01 & $(0.96-1.07)$ & 0.64 & 1.01 & $(0.98-1.04)$ & 0.51 \\
\hline Diagnosis of metastatic disease & 1.27 & $(0.88-1.84)$ & 0.20 & 1.07 & $(0.88-1.31)$ & 0.48 \\
\hline Diagnosis of other neoplasms & 1.20 & $(0.92-1.57)$ & 0.17 & 1.00 & $(0.86-1.16)$ & 0.97 \\
\hline Previous IV therapy & 0.73 & $(0.56-0.96)$ & 0.03 & 1.06 & $(0.91-1.24)$ & 0.46 \\
\hline Baseline total health care costs (per $\$ 1,000)$ & 1.03 & $(1.00-1.06)$ & 0.02 & 1.01 & $(1.00-1.03)$ & 0.13 \\
\hline Erlotinib out-of-pocket costs per prescription (per $\$ 100$ ) & 0.97 & $(0.95-0.98)$ & 0.0001 & 1.15 & $(1.13-1.17)$ & $<0.0001$ \\
\hline
\end{tabular}

Note: Intercept Only: -2 log likelihood 1671.394; Full Model: -2 log likelihood $1616.413 \mathrm{c} 2=54.9812 \mathrm{df}=17,0.0001 ; c=0.628$.

${ }^{a}$ Adherence defined as medication possession ratio $>80 \%$.

$C I=$ confidence interval; $d f=$ degrees of freedom; $H R=$ hazards ratio; $I V=$ intravenous; $O R=$ odds ratio.

to the low-income subsidy group, baseline costs, and out-ofpocket costs were significant factors associated with adherence. In the sensitivity analysis, when clinical variables from chart data were added to the model, coefficients for diagnosis of other neoplasms and stage IV disease were large in magnitude and statistically significant, implying that they are important predictors of adherence. It may be that patients with other neoplasms and/or at stage IV disease were under more continual care by their physicians and thus more likely to be adherent to their medication. 
TABLE 5 Evaluation of Potential Predictors of Adherence to and Duration of Treatment with Oral Erlotinib

\begin{tabular}{|c|c|c|c|c|c|c|}
\hline \multirow[b]{2}{*}{ Parameter } & \multicolumn{3}{|c|}{ Adherenceb ${ }^{b}$} & \multicolumn{3}{|c|}{ Persistence } \\
\hline & OR & $(95 \% \mathrm{CI})$ & $P$ Value & HR & $(95 \% \mathrm{CI})$ & $P$ Value \\
\hline Age, years & 1.02 & $(0.99-1.05)$ & 0.2409 & 1.00 & $(0.98-1.02)$ & 0.8951 \\
\hline Gender (male vs. female) & 1.41 & $(0.94-2.13)$ & 0.0996 & 0.82 & $(0.65-1.03)$ & 0.0905 \\
\hline Race/ethnicity (black/other vs. white) & 1.23 & $(0.71-2.13)$ & 0.4617 & 0.89 & $(0.67-1.20)$ & 0.4528 \\
\hline Patient's geographic region (Northeast vs. South) & 2.12 & $(0.66-6.77)$ & 0.3176 & 0.69 & $(0.35-1.38)$ & 0.2940 \\
\hline Patient's geographic region (West vs. South) & 1.52 & $(0.79-2.92)$ & 0.6841 & 0.75 & $(0.50-1.13)$ & 0.1641 \\
\hline Patient's geographic region (Midwest vs. South) & 1.06 & $(0.66-1.68)$ & 0.2552 & 1.11 & $(0.86-1.43)$ & 0.4277 \\
\hline Population density (urban vs. rural) & 1.10 & $(0.56-2.16)$ & 0.6366 & 0.89 & $(0.62-1.27)$ & 0.5153 \\
\hline Population density (suburban vs. rural) & 1.49 & $(0.71-3.14)$ & 0.1790 & 0.83 & $(0.55-1.25)$ & 0.3699 \\
\hline Low-income subsidy recipient (Medicare Advantage only) & 0.72 & $(0.34-1.55)$ & 0.4056 & 4.81 & $(2.76-8.38)$ & $<0.0001$ \\
\hline Dual eligible recipient (Medicare Advantage only) & 0.80 & $(0.38-1.70)$ & 0.5688 & 2.12 & $(1.22-3.66)$ & 0.0073 \\
\hline Line of business (commercial vs. Medicare) & 1.12 & $(0.45-2.81)$ & 0.8010 & 0.40 & $(0.24-0.66)$ & 0.0004 \\
\hline Deyo-Charlson Comorbidity Index & 1.00 & $(0.92-1.09)$ & 0.9884 & 1.01 & $(0.96-1.06)$ & 0.7620 \\
\hline Diagnosis of metastatic disease & 1.23 & $(0.66-2.31)$ & 0.5187 & 1.00 & $(0.73-1.37)$ & 0.9809 \\
\hline Diagnosis of other neoplasms & 1.95 & $(1.24-3.06)$ & 0.0039 & 1.01 & $(0.81-1.27)$ & 0.9027 \\
\hline Previous IV chemotherapy use for NSCLC & 0.72 & $(0.44-1.16)$ & 0.1778 & 1.30 & $(0.98-1.71)$ & 0.0675 \\
\hline Baseline total health care costs (per $\$ 1,000)$ & 1.02 & $(0.97-1.06)$ & 0.4687 & 1.01 & $(0.99-1.04)$ & 0.3015 \\
\hline Erlotinib out-of-pocket costs per prescription (per $\$ 100$ ) & 0.94 & $(0.91-0.97)$ & 0.0001 & 1.17 & $(1.14-1.19)$ & 0.0001 \\
\hline Histology (squamous cell vs. adenocarcinoma) & 1.18 & $(0.71-1.98)$ & 0.4695 & 0.98 & $(0.73-1.31)$ & 0.8690 \\
\hline Histology (other vs. adenocarcinoma) & 0.96 & $(0.52-1.79)$ & 0.6979 & 0.83 & $(0.58-1.18)$ & 0.3000 \\
\hline Staging (stage IV vs. not stage IV) & 1.59 & $(1.03-2.44)$ & 0.0355 & 0.91 & $(0.72-1.14)$ & 0.4128 \\
\hline
\end{tabular}

Note: Adherence Model=Intercept Only: -2 log likelihood 654.497; Full Model: -2 log likelihood 605.258 c2=41.9666 df=20, $P=0.0028 ; c=0.685$.

Persistence Model=Intercept Only: -2 log likelihood 3603.773; Full Model: -2 log likelihood 3428.987 c2=174.7860 df=21, P $\leq 0.0001$.

a Patients with chart data, $n=572$.

bAdherence defined as medication possession ratio $>80 \%$.

$C I=$ confidence interval; $d f=$ degrees of freedom; $H R=$ hazards ratio; $I V=$ intravenous; $N S C L C=$ non-small cell lung cancer; OR=odds ratio.

In contrast, diagnosis of other neoplasms and advanced disease did not seem to play a major role in the duration of treatment as seen in the persistence model. Possibly, while patients with advanced disease were adherent to their medication, progression of the disease may have affected further treatment decisions. Another difference in the persistence versus adherence model was that low-income subsidy status and dual eligibility helped patients stay on therapy for a longer period of time. Additionally, ORs associated with out-of-pocket costs were reversed in the persistence model, indicating that increased out-of-pocket costs were associated with longer duration on therapy. This is an interesting association, but the ORs were not large in magnitude and should be evaluated further. This retrospective claims analysis cannot be used to infer causality between these factors, so the interpretation is limited to the observed association. Overall, patients did not continue on therapy for extended periods of time (median duration of therapy was 120 days in the first-line setting and 96 days in the second-line setting). With short durations of therapy, it is very likely that patients were switched to other medications to manage their disease.

Adherence to therapy is a complex phenomenon to measure-there are gaps in data, and simplistic views must be applied to the complexity of disease and therapies used. Unlike other chronic diseases, cancer is often cared for by using a treat-to-progression approach, which requires a flexible time period for the adherence calculation rather than predetermined time intervals. In this study, variables from patient charts provided clinical insight to complement variables from claims data, explaining why some patients may have high adherence (taking their medication as prescribed) but shorter duration of therapy (disease progresses or intolerable adverse events occur, requiring discontinuation of treatment). As such, a targeted approach to removing barriers might focus on risk factors affecting adherence over persistence.

\section{Limitations}

This study has some limitations to consider. Similar to all retrospective analyses, there is a risk of gaps in information in the database (e.g., disease-specific information) and errors in claims coding. While Humana is a large national health plan with beneficiaries residing in a broad array of geographic regions, it may be difficult to generalize the results to the overall U.S. population.

Although a chart review was used to collect clinical information, valid chart information from the medical record was 
only available for $50.3 \%$ of the patients. As with all studies using MPR, claims data can only determine that the prescription was filled; it is unknown if the patient actually took the medication.

Factors related to adherence and treatment duration may be different for patients under hospice care than those not under hospice care. However, a small portion $(<18.0 \%)$ of patients included in this study were under hospice care during the postindex period, implying that the results were not likely driven by such patients. Additionally, claims data do not contain other factors such as social, behavioral, or physician characteristics, which have been reported in the literature to influence adherence.

The cost analyses do not include patient assistance programs or supplemental benefits, which may influence the actual out-of-pocket costs for patients. Finally, it was assumed that all refilled medications were billed and captured in the claims data; therefore, any refills that may have occurred and not been directly billed to insurance (e.g., free samples, during an inpatient stay) could have been missed in this analysis.

These results suggest the need to further explore the association between adherence, persistence, and the course of the disease in other data sources as well as for other oral cancer therapies and to improve the data collected in claims and in health records to better understand the factors and interrelationship of factors associated with adherence and persistence.

\section{Conclusions}

This study contributes important findings regarding factors associated with adherence and persistence to oral erlotinib treatment. The complementary data from patient charts and administrative claims provide a more comprehensive picture of the impact of clinical and demographic characteristics, baseline health care costs, and out-of-pocket costs on adherence and persistence. With the increased availability of oral medications in oncology, there is a need to continue to better understand these risk factors that affect adherence and early discontinuation of treatment. This understanding will enable physicians and other care providers to apply a targeted approach to remove any barriers to adherence and persistence.

\section{Authors}

LISA M. HESS, PhD; KATHERINE WINFREE, PhD; YAJUN E. ZHU, MS; and ANA B. OTON, MD, Eli Lilly and Company, Indianapolis, Indiana. ANTHONY LOUDER, PhD, and RADHIKA NAIR, PhD, Comprehensive Health Insights, Louisville, Kentucky.

AUTHOR CORRESPONDENCE: Lisa M. Hess, PhD, Eli Lilly and Company, LCC DC 2132, Indianapolis, IN 46285.

Tel.: 317.908.1872; E-mail: hess_lisa_m@lilly.com.

\section{DISCLOSURES}

This study was supported by funding from Eli Lilly and Company to Comprehensive Health Insights, a Humana company, as a collaborative research project involving employees of both companies. Hess, Winfree, Zhu, and Oton are employees of Eli Lilly and Company. Louder and Nair are employees of Comprehensive Health Insights, which received funding to complete this research.

Study concept and design were contributed by Hess, Zhu, Winfree, and Oton. Nair and Louder collected the data, and data interpretation was performed by all the authors. The manuscript was written primarily by Hess, along with Nair, and revised by Hess, Nair, Louder, and Winfree, with assistance from Zhu and Louder.

\section{REFERENCES}

1. Liu G, Franssen E, Fitch MI, Warner E. Patient preferences for oral versus intravenous palliative chemotherapy. J Clin Oncol. 1997;15(1):110-15.

2. O'Neill VJ, Twelves CJ. Oral cancer treatment: developments in chemotherapy and beyond. Br J Cancer. 2002;87(9):933-37.

3. Sokol MC, McGuigan KA, Verbrugge RR, Epstein RS. Impact of medication adherence on hospitalization risk and healthcare cost. Med Care. 2005;43(6):521-30.

4. Goren A, diBonaventura, Wagner R. Adherence and its association with health outcomes among patients currently treated for leukemia, melanoma, or non-small cell lung cancer. Value Health. 2013;16(3):Al44 [Abstract PCN95]. Available at: http://www.valueinhealthjournal.com/article/S1098-

3015(13)00780-8/abstract. Accessed February 23, 2017.

5. Goldberg SL, Aioub MS, Beluch WH, et al. Adherence to oral tyrosine kinase inhibitor therapy: results of a self-reported patient survey. Blood. 2011;118(21):Abstract 4432. Available at: http://www.bloodjournal.org/content/118/21/4432. Accessed February 23, 2017.

6. Aslam S, Tschida S, Lal LS, et al. Managing specialty medication services through a network of specialty pharmacies: a case of oral oncology medications. J Clin Oncol. 2011;29(Suppl):Abstract 6132. Available at: http://meetinglibrary.asco.org/content/78073-102. Accessed February 23, 2017.

7. Given BA, Spoelstra SL, Grant M. The challenges of oral agents as antineoplastic treatments. Semin Oncol Nurs. 2011;27(2):93-103.

8. Gramage C, Delgado T, Rodriguez SE, et al. Adherence to capecitabine chemotherapy. Presented at: European Association of Hospital Pharmacists, 17th Congress of the EAHP; Milan, Italy; March 21-23, 2012. Available at: www.eahp.eu/sites/default/files/grp095.pdf. Accessed February 23, 2017.

9. Korpanty GJ, Graham DM, Vincent MD, Leighl NB. Biomarkers that currently affect clinical practice in lung cancer: EGFR, ALK, MET, ROS-1, and KRAS. Front Oncol. 2014;4:204.

10. Hess LM, Goodloe R, Cui ZL, Carter GC, Beyrer J, Treat J. Comparative effectiveness of second-line treatment for non-small cell lung cancer (NSCLC) among patients $\geq 70$ versus $<70$ years of age. J Clin Oncol. 2015;33(Suppl):e19018

11. Timmers L, Boons CC, Moes-Ten Hove J, et al. Adherence, exposure and patients' experiences with the use of erlotinib in non-small cell lung cancer. J Cancer Res Clin Oncol. 2015;141(8):1481-91

12. Gebbia V, Bellavia M, Banna GL, et al. Treatment monitoring program for implementation of adherence to second-line erlotinib for advanced nonsmall-cell lung cancer. Clinical Lung Cancer. 2013;14(4):390-98.

13. Lucca JV, Hooper CL, Boucher J, Pedulla LV, Berry DL, Marcoux JP. A pilot study of direct care nurse (DCN) education to improve adherence and knowledge of erlotinib in patients with non-small cell lung cancer. J Clin Oncol. 2012;30(Suppl):e19637.

14. Sabaté E. Adherence to Long-Term Therapies: Evidence for Action. Geneva: World Health Organization; 2003. Available at: http://www.who.int/chp/ knowledge/publications/adherence_full_report.pdf. Accessed February 17, 2017. 
15. Neuss MN, Polovich M, McNiff K, et al. 2013 updated American Society of Clinical Oncology/Oncology Nursing Society chemotherapy administration safety standards including standards for the safe administration and management of oral chemotherapy. Oncol Nurs Forum. 2013;40(3):225-33.

16. Haynes RB, Sackett DL, Taylor DW, Roberts RS, Johnson AL. Manipulation of the therapeutic regimen to improve compliance: conceptions and misconceptions. Clinical Pharmacol Ther. 1977;22(2):125-30.

17. Greenberg RN. Overview of patient compliance with medication dosing: a literature review. Clin Ther. 1984;6(5):592-99.

18. Blackwell B, Bloomfield SS, Buncher CR. Demonstration to medical students of placebo responses and non-drug factors. Lancet. 1972;1(7763):1279-82.

19. Hess LM, Raebel MA, Conner DA, Malone DC. Measurement of adherence in pharmacy administrative databases: a proposal for standard definitions and preferred measures. Ann Pharmacother. 2006;40(7-8):1280-88.

20. Leslie SR, Gwadry-Sridhar F, Thiebaud P, Patel BV. Calculating medication compliance, adherence and persistence in administrative claims databases. Pharm Programming. 2008;1:13-19.
21. Centers for Medicare \& Medicaid Services. Medicare health and drug plan quality and performance ratings 2013 Part C \& Part D. Technical notes. 2012. Available at: https://www.cms.gov/medicare/prescription-drugcoverage/prescriptiondrugcovgenin/downloads/2013-part-c-and-d-preview2-technical-notes-v090612-.pdf. Accessed February 17, 2017.

22. Pharmacy Quality Alliance. PDQ performance measures. Proportion of days covered (PDC). December 2016. Available at: www.pqaalliance.org/ measures/default.asp. Accessed March 3, 2017.

23. National Institute for Health and Care Excellence. Medicines adherence: involving patients in decisions about prescribed medicines and supporting adherence. Clinical guideline [CG76]. January 2009. Available at: https:// www.nice.org.uk/guidance/cg76. Accessed February 17, 2017.

24. Wilson J, Bock A. The benefit of using both claims data and electronic medical record data in health care analysis. Optum white paper. 2012. Available at: https://www.optum.com/content/dam/optum/resources/ whitePapers/Benefits-of-using-both-claims-and-EMR-data-in-HC-analysisWhitePaper-ACS.pdf. Accessed February 17, 2017. 